\title{
Chidamide, a histone deacetylase inhibitor, induces growth arrest and apoptosis in multiple myeloma cells in a caspase-dependent manner
}

\author{
XIANG-GUI YUAN ${ }^{*}$, YU-RONG HUANG ${ }^{*}$, TENG YU, HUA-WEI JIANG, YANG XU and XIAO-YING ZHAO \\ Department of Hematology, The Second Affiliated Hospital, \\ Zhejiang University School of Medicine, Hangzhou, Zhejiang 310009, P.R. China
}

Received August 1, 2018; Accepted March 29, 2019

DOI: $10.3892 / \mathrm{ol} .2019 .10301$

\begin{abstract}
Chidamide, a novel histone deacetylase (HDAC) inhibitor, induces antitumor effects in various types of cancer. The present study aimed to evaluate the cytotoxic effect of chidamide on multiple myeloma and the underlying mechanisms involved. Viability of multiple myeloma cells upon chidamide treatment was determined by the Cell Counting Kit-8 assay. Apoptosis induction and cell cycle alteration were detected by flow cytometry. Specific apoptosis-associated proteins and cell cycle proteins were evaluated by western blot analysis. Chidamide suppressed cell viability in a timeand dose-dependent manner. Chidamide treatment markedly suppressed the expression of type I HDACs and further induced the acetylation of histones $\mathrm{H} 3$ and $\mathrm{H} 4$. In addition, it promoted $G_{0} / G_{1}$ arrest by decreasing cyclin D1 and c-myc expression, and increasing phosphorylated-cellular tumor antigen p53 and cyclin-dependent kinase inhibitor 1 (p21) expression in a dose-dependent manner. Treatment with chidamide induced cell apoptosis by upregulating the apoptosis regulator Bax/B-cell lymphoma 2 ratio in a caspase-dependent manner. In addition, the combination of chidamide with bortezomib, a proteasome inhibitor widely used as a therapeutic agent for multiple myeloma, resulted in enhanced inhibition of cell viability. In conclusion, chidamide induces a marked antimyeloma effect by inducing $\mathrm{G}_{0} / \mathrm{G}_{1}$ arrest and apoptosis via a caspase-dependent pathway. The present study provides evidence for the clinical application of chidamide in multiple myeloma.
\end{abstract}

Correspondence to: Professor Xiao-Ying Zhao, Department of Hematology, The Second Affiliated Hospital, Zhejiang University School of Medicine, 88 Jiefang Road, Hangzhou, Zhejiang 310009, P.R. China

E-mail: zrxz@zju.edu.cn

${ }^{*}$ Contributed equally

Key words: chidamide, histone deacetylase inhibitors, cell cycle, $\mathrm{G}_{0} / \mathrm{G}_{1}$ arrest, apoptosis, multiple myeloma

\section{Introduction}

Multiple myeloma (MM) is the second most frequent hematological neoplasm in the USA in 2018 (1) and is characterized by the infiltration of clonal plasma cells in the bone marrow, secretion of monoclonal immunoglobulins and end organ damage (2). Over the last decade, the introduction of proteasome inhibitors [bortezomib (BTZ) and carfilzomib] and immunomodulatory drugs (thalidomide and lenalidomide), combined with autologous stem cell transplantation, have significantly improved the prognosis of patients with MM. The 5-year overall survival (OS) rate of patients diagnosed between 2005 and 2011 was nearly double the rate of patients diagnosed between 1975 and 1977 (49 and 25\%, respectively) (3). However, MM remains an incurable disease, and the majority of patients will eventually relapse and become chemorefractory to currently available drugs. Therefore, further development of novel therapies is required.

Histone deacetylase (HDAC) inhibitors (HDACIs), are believed to be promising therapeutic drugs in the treatment of cancer. To date, only 4 HDACIs (panobinostat, belinostat, romidepsin and vorinostat) have been approved by the US Food and Drug Administration (FDA) for the treatment of several types of cancer. Deregulation of histone acetylation has been recognized to serve a critical role in the pathogenesis of MM (4). HDACs are overexpressed in plasma cells derived from patients with MM, compared with those from healthy controls. High expression levels of HDAC1 protein are associated with decreased overall survival time (OS) in patients with MM (4). In addition, HDACI treatment induces the upregulation of 21 genes, which were reported to be associated with improved OS in MM (5). Therefore, HDACs have been considered promising targets for MM therapies. Several HDACI-based regimens are in clinical trials for MM, with overall response rates of $42-61 \%$ (6-8). The phase 3 study PANORAMA-1 demonstrated that the chemotherapy regimen including panobinostat (a pan-HDACI) resulted in a longer progression-free survival, when compared with that in the placebo group (7). As a result, panobinostat was approved by the FDA for the treatment of relapsed/refractory MM in 2015. However, a number of adverse events have been observed with pan-HDACIs, including diarrhea, anorexia, nausea, fatigue, 
thrombus and thrombocytopenia (7). To reduce the adverse events of pan-HDACIs, selective HDACIs targeting class I isoforms with improved efficacy and lower toxicity may be promising drugs for the treatment of MM (9).

Chidamide (CM), a novel benzamide type HDACI, selectively suppresses the activity of class I HDACs, including HDAC1, HDAC2, HDAC3 and HDAC10 (10,11). Previous studies have revealed that $\mathrm{CM}$ induces cell proliferation inhibition and apoptosis in several hematological malignancies, including myelodysplastic syndromes (12), leukemia (13-15) and natural killer (NK)/T-cell lymphoma (16), as well as non-hematological malignancies, including lung cancer (17), hepatocellular carcinoma (18), colon cancer (19) and pancreatic cancer (20). CM was approved by the China FDA for the treatment of peripheral T-cell lymphoma (PTCL) in 2014 (21). A study in 2017 revealed that the overall response rate to $\mathrm{CM}$ alone or in combination was 39.06 and $51.18 \%$, respectively, for relapsed/refractory PTCL (22). At present, clinical trials of CM are being conducted in China and the US for the treatment of solid tumors. However, to the best of our knowledge, its biological effects on MM and relevant mechanisms have not been investigated.

In the present study, the cytotoxic effect of CM on MM cells was evaluated and the possible mechanisms involved were investigated. The aim of the present study was to provide evidence for the clinical application of chidamide in multiple myeloma.

\section{Materials and methods}

Cell lines and cell culture. The human MM RPMI8226 and U266 cell lines were obtained from the Hematology Institute of Zhejiang University (Hangzhou, China). All cells were cultured in a humidified atmosphere containing $5 \% \mathrm{CO}_{2}$ at $37^{\circ} \mathrm{C}$. All cells were maintained in RPMI-1640 medium with $10 \%$ fetal bovine serum, penicillin $(100 \mathrm{U} / \mathrm{ml})$ and streptomycin $(100 \mu \mathrm{g} / \mathrm{ml})$ (all Gibco; Thermo Fisher Scientific, Inc. Waltham, MA, USA). Bone marrow was collected from 4 newly diagnosed patients with MM admitted to the Second Affiliated Hospital, Zhejiang University School of Medicine (Hangzhou, China) between January 2018 and March 2018. Patient 1 was a 59 -year-old male with $\mathrm{IgG} / \kappa$ subtype, patient 2 was a 58 -year-old male with $\mathrm{IgG} / \lambda$ subtype, patient 3 was a 72 -year-old male with $\operatorname{IgG} / \lambda$ subtype and patient 4 was a 77 -year-old female with $\mathrm{IgG} / \lambda$ subtype. Once informed consent was obtained, an additional $3 \mathrm{ml}$ of bone marrow was extracted during the diagnostic bone marrow puncture. Subsequently, primary myeloma cells were isolated by Ficoll-Hypaque density gradient centrifugation $(2,000 \mathrm{x} \mathrm{g}, 15 \mathrm{~min}$ at room temperature). All experiments were performed according to the protocol approved by the Ethics Committee, The Second Affiliated Hospital, Zhejiang University School of Medicine (approval no. 2019022; Hangzhou, China).

Reagents and antibodies. CM was obtained from Shenzhen Chipscreen Biosciences Co., Ltd. (Shenzhen, China). CM was prepared in dimethylsulfoxide (DMSO) and stored at $-20^{\circ} \mathrm{C}$ at $20 \mathrm{mmol} / \mathrm{l}$. The final concentration of DMSO in the culture medium was $<0.1 \%$. The molecular weight of CM is 747.25 and its formula is provided in Fig. 1A. BTZ was purchased from Xian Janssen Pharmaceutical Ltd. (Beijing, China). Anti-c-myc (cat. no. 9402), anti-caspase-3 (cat. no. 9662), anti-caspase-8 (cat. no. 4790), anti-cleaved-caspase-8 (cat. no. 9496), anti-caspase-9 (cat. no. 9502), anti-Bcl-2 (cat. no. 15071), anti-myeloid cell leukemia 1 (mcl-1; cat. no. 94296), anti-t-p53 (cat. no. 2524), anti-p-p53 (cat. no. 2521), anti-Bax (cat. no. 5023), anti-p21 (cat. no. 2947), anti-cyclin D1 (cat. no. 2922), anti-HDAC1 (cat. no. 5356), anti-HDAC2 (cat. no. 2540) and anti-HDAC3 (cat. no. 3949) antibodies were obtained from Cell Signaling Technology, Inc. (Danvers, MA, USA). Anti-GAPDH (cat. no. ab181602), horseradish peroxidase (HRP)-conjugated goat anti-rabbit secondary antibody (cat. no. ab6721), HRP-conjugated goat anti-mouse secondary antibody (cat. no. ab6789), anti-acetyl-histone H3 (acetyl K9 + K14 + K18 + K23 + K27; cat. no. ab47915) and anti-acetyl-histone $\mathrm{H} 4$ (acetyl $\mathrm{K} 5+\mathrm{K} 8+\mathrm{K} 12+\mathrm{K} 16$; cat. no. ab177790) antibodies were obtained from Abcam (Cambridge, MA, USA). The anti-poly ADP ribose polymerase (PARP) antibody (cat. no. sc53643) was obtained from Santa Cruz Biotechnology, Inc. (Dallas, TX, USA). All antibodies from Cell Signaling Technology and Santa Cruz Biotechnology were diluted at 1:1,000 and all antibodies from Abcam were diluted at 1:10,000.

Cell viability assay. Cells were seeded in 96-well plates at $2 \times 10^{4}$ cells/well and incubated in $0.25-8 \mu \mathrm{mol} / \mathrm{l} \mathrm{CM}$ for 24,48 or $72 \mathrm{~h}$. Following treatment, cell viability was measured using the Cell Counting Kit-8 (CCK-8) viability assay (Dojindo Molecular Technologies, Inc., Kumamoto, Japan). According to the manufacturer's instruction, $10 \mu \mathrm{lCCK}-8$ solution was added to each well for $3 \mathrm{~h}$ at $37^{\circ} \mathrm{C}$. The optical density (OD) was measured at $450 \mathrm{~nm}$ using a microplate reader (Biotek, Winooski, VT, USA). To determine whether CM sensitized MM cells to BTZ, the cells were cultured with media containing $0.5 \mu \mathrm{mol} / 1 \mathrm{CM}$ for RPMI8226 cells or $2 \mu \mathrm{mol} / 1 \mathrm{CM}$ for U266 cells in the absence or presence of BTZ (2.5 and $5 \mathrm{ng} / \mathrm{ml}$ ) for $24 \mathrm{~h}$, and subsequently cell viability was assessed using the CCK-8 assay. The cell viability was calculated as [OD (treatment)-OD (control)]/[OD (control)-OD (blank)] $x 100$. The viability inhibition rate $(\%)$ was calculated as [100-cell viability rate (\%)]. Time- and dose-response curves were produced using GraphPad Prism 5 (GraphPad Software Inc., San Diego, CA, USA). IC $_{50}$ values were predicted based on the available data using the SPSS probit model analysis (SPSS v17.0; SPSS, Inc., Chicago, IL, USA).

Western blot analysis. Following exposure to CM $(0,0.5,1$, $2 \mu \mathrm{mol} / 1$ for PRMI8226 cells, and 0, 2, 4, $8 \mu \mathrm{mol} / 1$ for U266 cells) for $48 \mathrm{~h}$, the cells were harvested and washed with ice-cold PBS. Proteins were extracted using ice-cold radioimmunoprecipitation assay lysis buffer (Beyotime Institute of Biotechnology) with phenylmethylsulfonyl fluoride. Following a brief sonication, the cell lysates were kept on ice and subsequently centrifuged at $15,984 \mathrm{x}$ g for $10 \mathrm{~min}$. Supernatant was collected and the protein concentrations were quantified with a bicinchoninic acid assay (Beyotime Institute of Biotechnology) according to the manufacturer's protocol. Total protein (40 $\mu \mathrm{g} /$ lane) was separated using 10-12\% SDS-PAGE and transferred to polyvinylidene fluoride membranes (EMD Millipore, Billerica, MA, USA). The membrane was 
A<smiles>CCCCCCCCON=O</smiles>

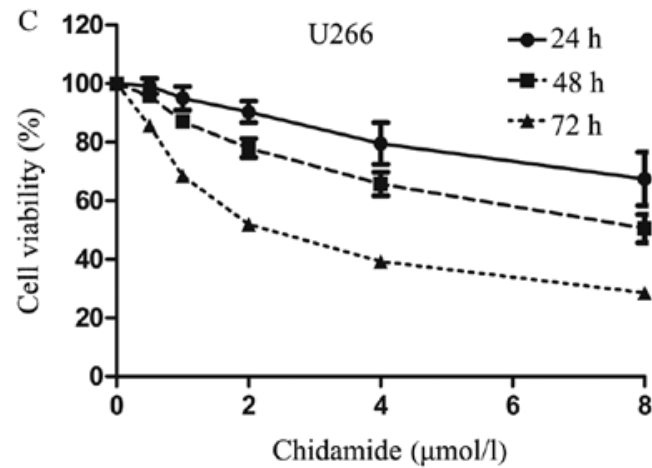

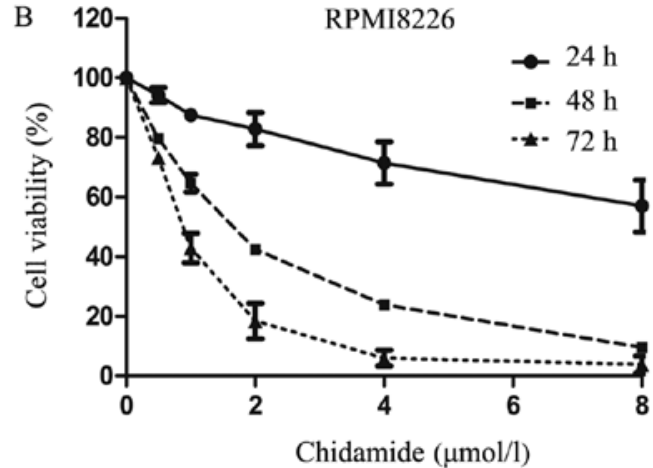

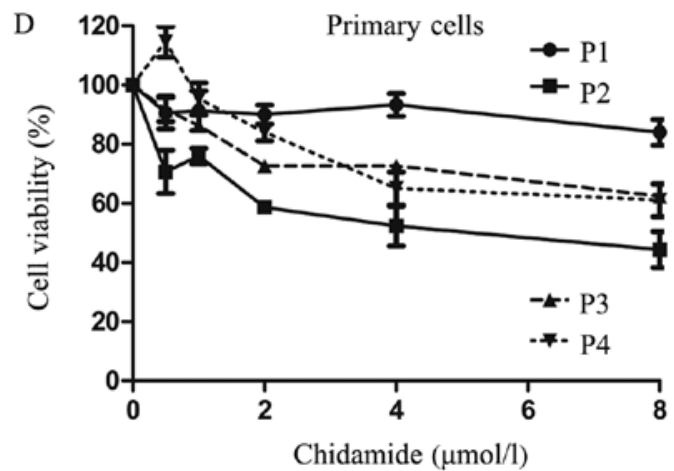

Figure 1. Chidamide inhibits the viability of myeloma cells and sensitizes myeloma cells to bortezomib. (A) The structural formula of chidamide (molecular weight, 747.25). (B) RPMI8226 cells and (C) U266 cells were treated with $0.25-8 \mu \mathrm{mol} / 1$ chidamide for 24,48 and $72 \mathrm{~h}$, and cell viability was measured using the CCK-8 assay. (D) Primary myeloma cells from 4 patients were treated with $0.25-8 \mu \mathrm{mol} / 1$ chidamide for $48 \mathrm{~h}$ and cell viability was measured using the CCK-8 assay. CCK-8, Cell Counting Kit-8.

subsequently blocked with TBST (0.05\% Tween-20) containing $5 \%$ skimmed milk for $1 \mathrm{~h}$ and probed overnight with the corresponding primary antibodies (diluted in primary antibody dilution buffer from Beyotime Institute of Biotechnology) at $4^{\circ} \mathrm{C}$. Subsequently the membrane was washed with TBST, exposed to the corresponding HRP-conjugated secondary antibodies for $1 \mathrm{~h}$ at room temperature, and detected by enhanced chemiluminescence (EMD Millipore).

Flow cytometric analysis. Apoptosis was investigated using an Annexin V-fluorescein isothiocyanate (FITC) apoptosis kit according to the manufacturer's protocol (BD Biosciences, San Jose, CA, USA). Briefly, following CM treatment $(0,0.5,1,2 \mu \mathrm{mol} / 1$ for PRMI8226 cells, and $0,2,4,8 \mu \mathrm{mol} / 1$ for U266 cells) for $48 \mathrm{~h}$, the cells were harvested and washed with ice-cold PBS and adjusted to $1 \times 10^{6}$ cells $/ \mathrm{ml}$ with binding buffer. Subsequently, the cells were incubated with $5 \mu 1$ FITC-labeled Annexin V and $5 \mu \mathrm{l}$ propidium iodide (PI) at room temperature in the dark for $15 \mathrm{~min}$. Finally, the stained cells were analyzed using a flow cytometer (BD Biosciences). The storing and processing of data was performed with FlowJo software v10.0.7 (Tree Star, Inc., Ashland, OR, USA).

Cell cycle analysis was also performed by flow cytometry. Following CM treatment (0, 0.5, 1, $2 \mu \mathrm{mol} / 1$ for PRMI8226 cells, and $0,2,4,8 \mu \mathrm{mol} / 1$ for U266 cells) for $48 \mathrm{~h}$, the cells were washed with ice-cold PBS and subsequently fixed in $70 \%$ ice-cold ethanol overnight. Subsequently, the cells were harvested and incubated in PBS with $100 \mathrm{mg} / \mathrm{ml} \mathrm{PI}$ and $100 \mu \mathrm{g} / \mathrm{ml} \mathrm{RNase} \mathrm{A}$ for $30 \mathrm{~min}$ (Beyotime Institute of Biotechnology). The PI-stained cells were subjected to cell cycle profiling analysis using a flow cytometer (BD Biosciences). Finally, the cell-cycle distribution was analyzed using ModFit LT software (v3.1, Verity Software House, Inc., Topsham, ME, USA).

Morphological analysis of apoptosis. To investigate the effect of CM on cell morphology, myeloma cells were treated in the presence or absence of CM $(2 \mu \mathrm{mol} / 1$ for PRMI8226 cells, and $8 \mu \mathrm{mol} / 1$ for U266 cells) for $48 \mathrm{~h}$. Cytospin slides were prepared and subsequently stained with Giemsa-Wright staining for $20 \mathrm{~min}$ at room temperature. Cell morphology was observed under a light microscope (x400 magnification). Characteristics of apoptosis including nuclear fragmentation, chromatin condensation and apoptotic bodies were observed.

Statistical analysis. All data are presented as the means \pm standard deviation for $\geq 3$ separate experiments. All analyses were performed using SPSS. Inter-group comparison was performed using 2-sided Student's t-test (2 groups) or one-way analysis of variance ( $\geq 3$ groups), followed by a Student-Newman-Keuls test for subsequent multiple comparisons between groups. $\mathrm{P}<0.05$ was considered to indicate a statistically significant difference.

\section{Results}

CM suppresses the viability of myeloma cell lines and primary myeloma cells. The effect of CM on myeloma cell lines (RPMI8226 and U266) and primary myeloma cells from 4 patients with MM was investigated using the CCK-8 


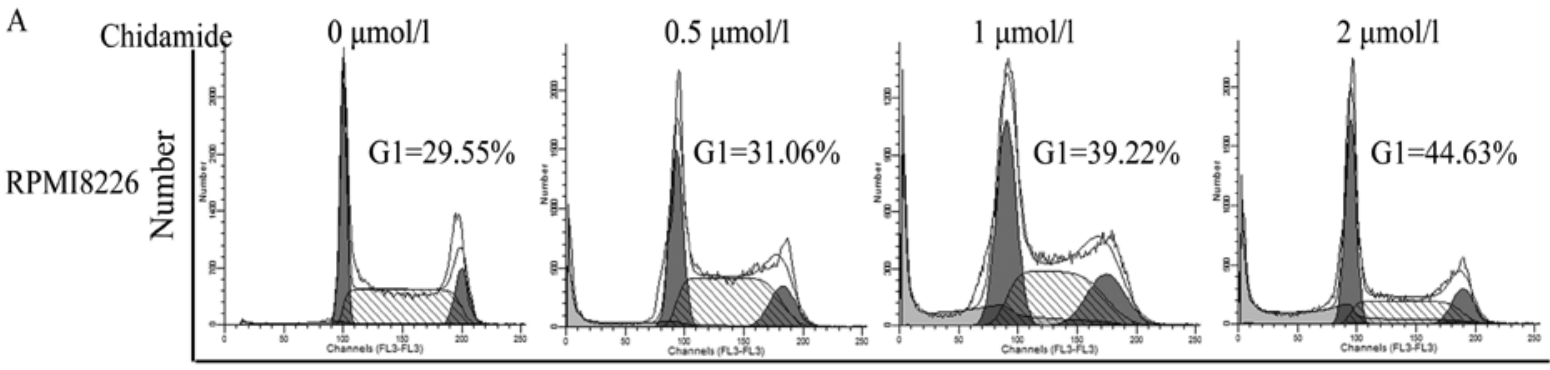

Channels (FL3-FL3)

B

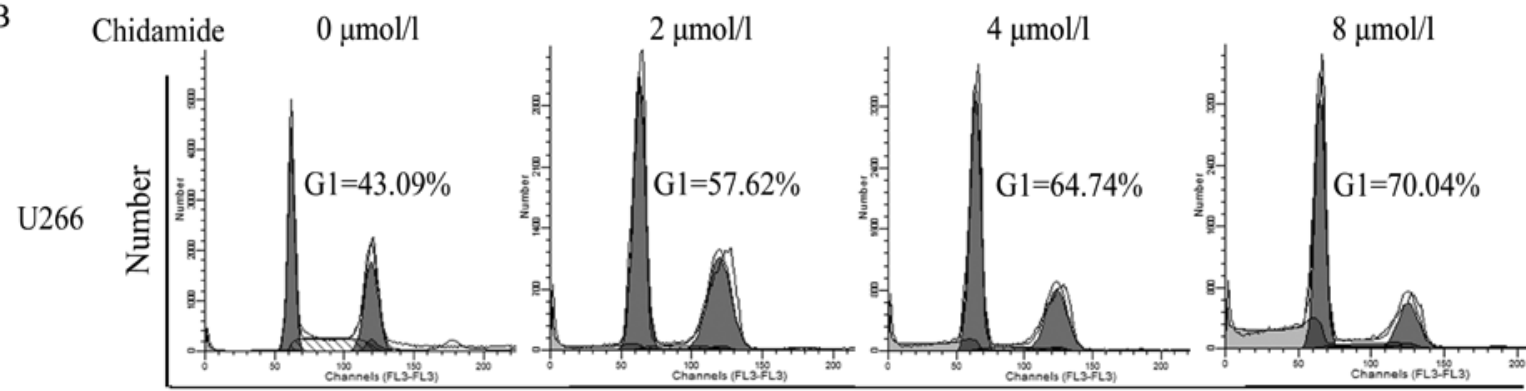

$\mathrm{C}$

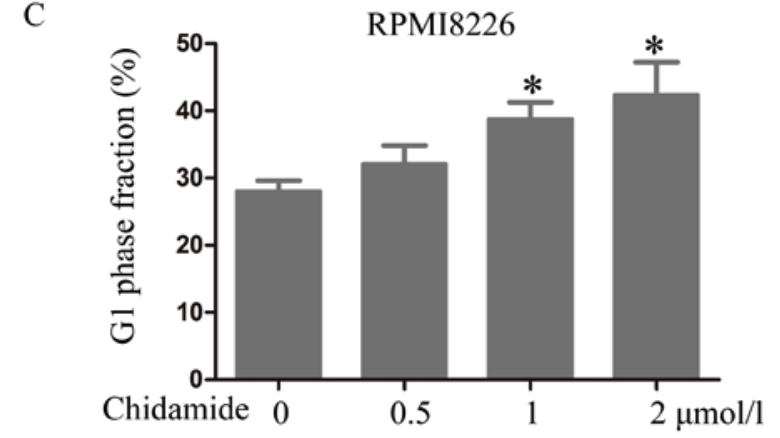

Channels (FL3-FL3)

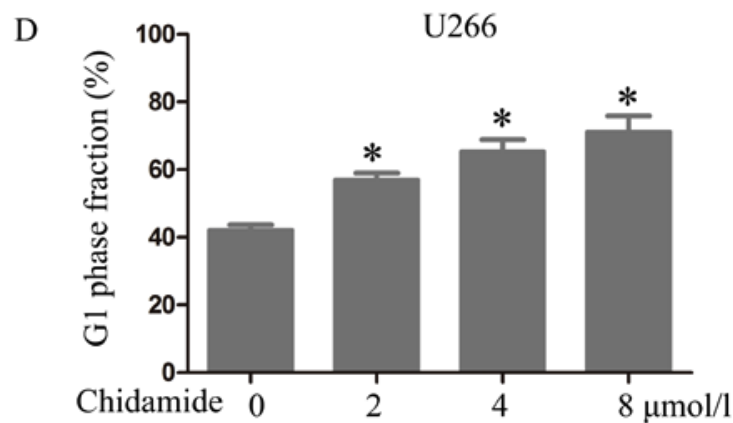

Figure 2. Chidamide induces $\mathrm{G}_{0} / \mathrm{G}_{1}$ phase arrest in myeloma cells. (A) RPMI8226 cells were treated with $(0,0.5,1,2 \mu$ mol/l) chidamide for $48 \mathrm{~h}$ and (B) $\mathrm{U} 266$ cells were treated with $(0,2,4,8 \mu \mathrm{mol} / \mathrm{l})$ chidamide for $48 \mathrm{~h}$, and subsequently cell cycle phases were assessed using flow cytometry (typical results from one experiment are presented). The $\mathrm{G}_{1}$ phase fraction of (C) RPMI8226 cells and (D) U266 cells following 48-h chidamide treatment. The quantitative data were pooled from three independent experiments. ${ }^{*} \mathrm{P}<0.05$ vs. no treatment.

assay. The $50 \%$ inhibitory concentration $\left(\mathrm{IC}_{50}\right)$ was measured using different concentrations (0.25-8 $\mu \mathrm{mol} / 1$ for 24-72 h). $\mathrm{CM}$ inhibited the viability of the MM cell lines in a time- and dose-dependent manner (Fig. $1 \mathrm{~B}$ and $\mathrm{C}$ ). The $\mathrm{IC}_{50}$ values at 24,48 and $72 \mathrm{~h}$ were significantly different from each other in RPMI8226 and U266 cells; the $\mathrm{IC}_{50}$ values in the RPMI8226 cells were $9.09 \pm 0.58,1.19 \pm 0.36$ and $0.77 \pm 0.21 \mu \mathrm{mol} / 1$ $(\mathrm{P}<0.001)$, respectively, whereas the values for the U266 cells were $16.16 \pm 2.51,8.06 \pm 1.02$ and $2.86 \pm 0.58 \mu \mathrm{mol} / 1(\mathrm{P}<0.001)$, respectively. The sensitivity of primary myeloma cells to $\mathrm{CM}$ was lower compared with that of the myeloma cell lines, with $48 \mathrm{~h} \mathrm{IC}_{50}$ values between 5.08 and $14.21 \mu \mathrm{mol} / \mathrm{l}$ (patient 1 was not sensitive to $\mathrm{CM}$ and the $\mathrm{IC}_{50}$ could not be calculated; $\mathrm{IC}_{50}$ for patient 2 was $5.08 \pm 0.47 \mu \mathrm{mol} / 1 ; \mathrm{IC}_{50}$ for patient 3 was $13.96 \pm 0.64 \mu \mathrm{mol} / \mathrm{l} ; \mathrm{IC}_{50}$ for patient 4 was $14.21 \pm 1.03 \mu \mathrm{mol} / \mathrm{l}$ ) (Fig. 1D).

$C M$ induces $G_{0} / G_{1}$ phase arrest in myeloma cells. To investigate whether CM alters the cell cycle, the DNA content of the cells was examined (PI staining) using flow cytometry. The cell cycle analysis demonstrated that $C M$ induced $G_{0} / G_{1}$ phase arrest in the RPMI8226 and U266 cells (Fig. 2). The cell number within the $\mathrm{G}_{0} / \mathrm{G}_{1}$ phase increased from $28.12 \pm 1.50$ to $42.42 \pm 4.80 \%$ in the RPMI8226 cells following exposure to $2 \mu \mathrm{mol} / \mathrm{l} \mathrm{CM}$ for $48 \mathrm{~h}$ compared with no $\mathrm{CM}$ treatment $(P=0.008)$. The number of cells within the $G_{0} / G_{1}$ phase increased from $42.31 \pm 1.43$ to $71.25 \pm 4.65 \%$ in the U266 cells following exposure to $8 \mu \mathrm{mol} / 1 \mathrm{CM}$ for $48 \mathrm{~h}$ compared with no CM treatment $(\mathrm{P}<0.001)$.

CM induces apoptosis in MM cell lines. To demonstrate whether the inhibition of cell viability was due to the induction of cell apoptosis, flow cytometry with Annexin V positive staining (the lower right and upper right quadrants represent cells undergoing apoptosis) was used. Following treatment for $48 \mathrm{~h}, \mathrm{CM}$ significantly promoted apoptosis in a dose-dependent manner in the RPMI8226 and U266 cells. Compared with untreated cells, the proportion of apoptotic cells increased from $7.12 \pm 2.50$ to $31.51 \pm 4.52 \%$ in the RPMI8226 cells following exposure to $2 \mu \mathrm{mol} / 1 \mathrm{CM}$ for $48 \mathrm{~h}(\mathrm{P}<0.001$; Fig. 3A, C) and from $6.82 \pm 2.41$ to $18.21 \pm 3.51 \%$ in the $\mathrm{U} 266$ cells following exposure to $8 \mu \mathrm{mol} / \mathrm{l} \mathrm{CM}$ for $48 \mathrm{~h}(\mathrm{P}=0.004$; Fig. 3B, D).

To confirm the apoptotic effect of $\mathrm{CM}$, morphological observation was performed using Giemsa-Wright staining. 


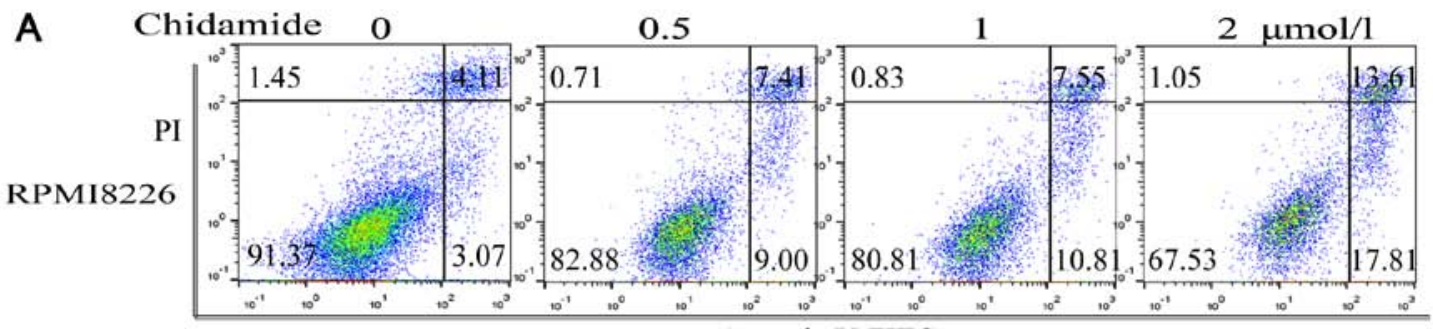

B
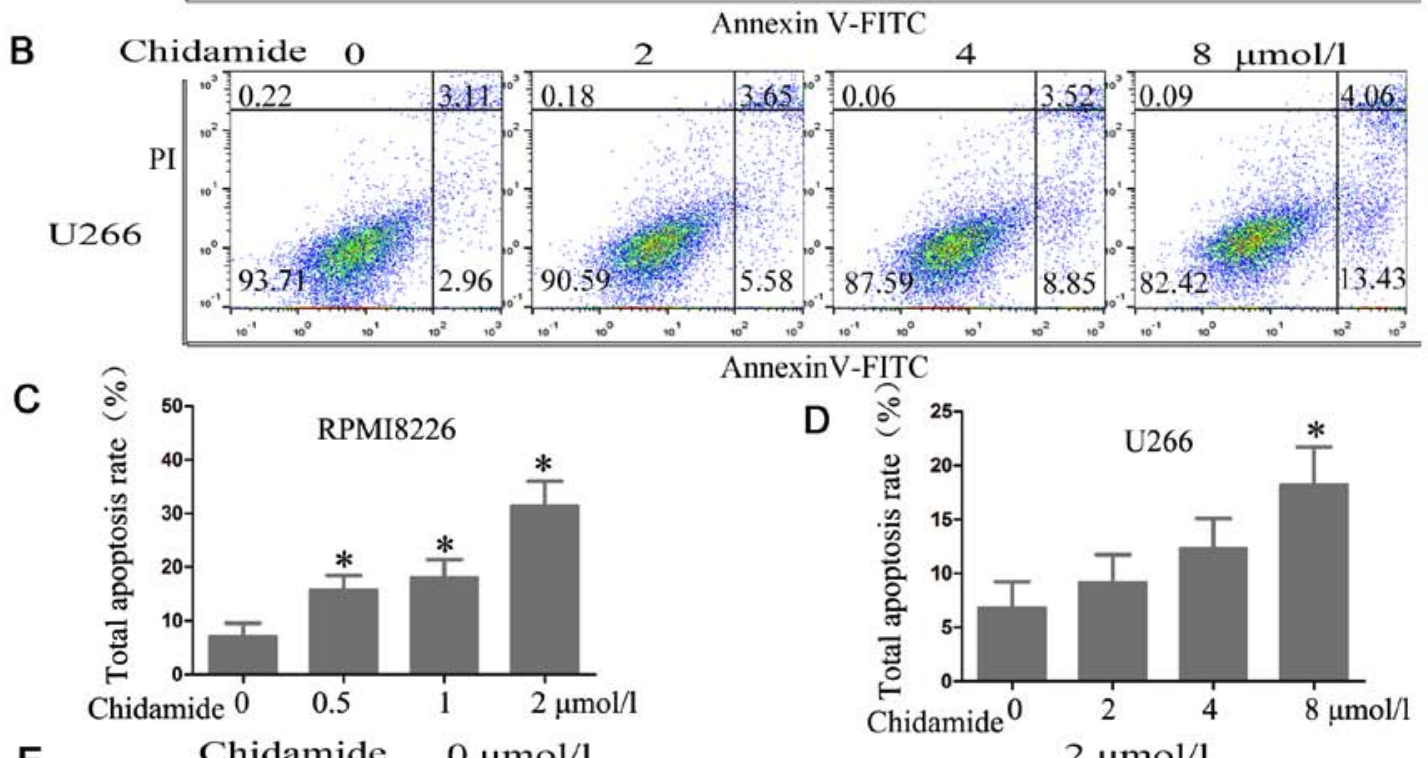

E
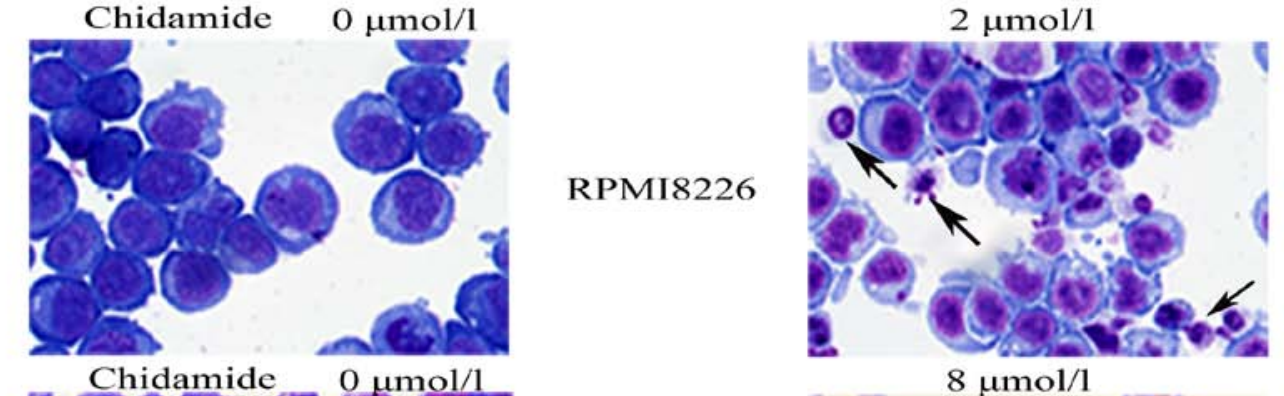

$\mathrm{F}$
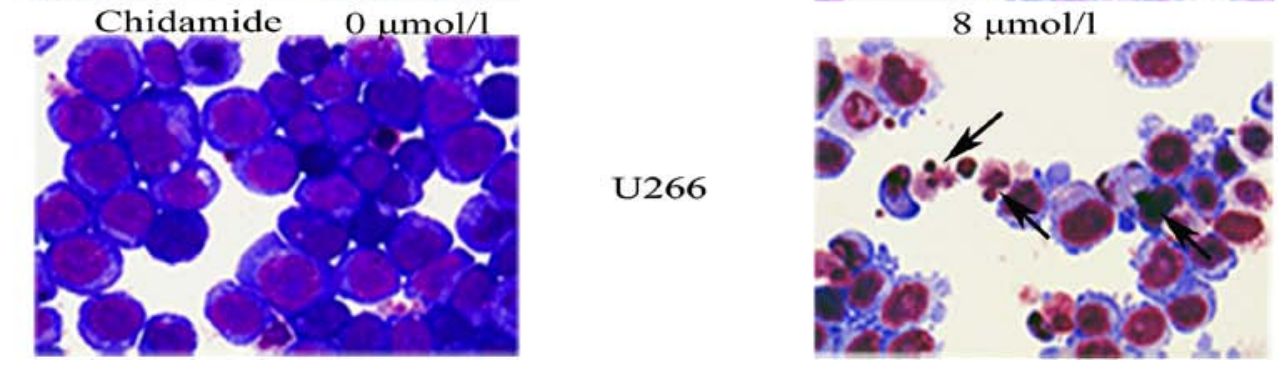

Figure 3. Chidamide induces apoptosis in myeloma cells. (A) RPMI8226 cells were treated with $(0,0.5,1,2 \mu \mathrm{mol} / 1)$ chidamide for $48 \mathrm{~h}$ and (B) U266 cells were treated with $(0,2,4,8 \mu \mathrm{mol} / \mathrm{l})$ chidamide for $48 \mathrm{~h}$, then the percentages of apoptotic cells were assessed by Annexin V-FITC/PI flow cytometry (typical results from one experiment are presented). The total apoptosis rate of (C) RPMI8226 cells and (D) U266 cells following chidamide treatment for $48 \mathrm{~h}$. The quantitative data were pooled from three independent experiments. ${ }^{*} \mathrm{P}<0.05$ vs. no treatment. Giemsa-Wright staining of (E) RPMI8226 and (F) U266 cells was performed following treatment in the presence or absence of chidamide ( $2 \mu \mathrm{mol} / 1$ for RPMI8226 cells and $8 \mu \mathrm{mol} / 1$ for U266 cells) for $48 \mathrm{~h}$ (x400 magnification). The arrows indicate typical apoptotic cells including nuclear fragmentation, chromatin condensation and apoptotic bodies. FITC, fluorescein isothiocyanate; PI, propidium iodide.

The morphology of myeloma cells treated in the presence or absence of $\mathrm{CM}(2 \mu \mathrm{mol} / 1$ for RPMI8226 cells and $8 \mu \mathrm{mol} / 1$ for U266 cells) for $48 \mathrm{~h}$ was examined. Morphological changes, including nuclear fragmentation, chromatin condensation and apoptotic bodies, which are characteristics of apoptosis, were observed (Fig. 3E and F).

$C M$ decreases the expression of HDACs and increases the acetylation levels of histones $\mathrm{H} 3$ and $\mathrm{H} 4$. To investigate the possible mechanisms of $\mathrm{CM}$, the expression of class I HDACs (HDAC1, HDAC2 and HDAC3) in MM cells was evaluated by western blot analysis. CM treatment markedly suppressed the expression of HDAC1, HDAC2 and HDAC 3 in a dose-dependent manner in RPMI8226 (Fig. 4A) and U266 cells (Fig. 4B) following treatment for $48 \mathrm{~h}$. In addition, the acetylation of histones $\mathrm{H} 3$ and $\mathrm{H} 4$ was also markedly increased following exposure to CM for $48 \mathrm{~h}$ for the RPMI8226 and U266 cells. These results demonstrate that CM can inhibit class I HDAC 


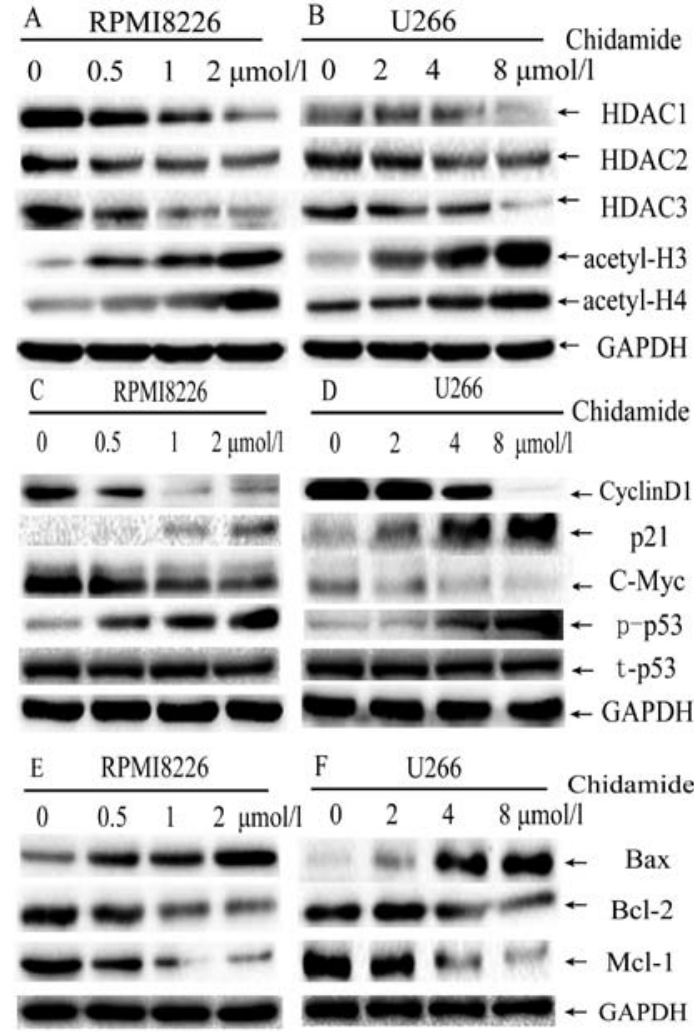

Figure 4. Molecular mechanisms of chidamide-mediated cell cycle arrest and apoptosis induction in myeloma cell lines. (A) RPMI8226 cells were treated with $0,0.5,1$ or $2 \mu \mathrm{mol} / 1$ chidamide for $48 \mathrm{~h}$ and (B) U266 cells were treated with $0,2,4$ or $8 \mu \mathrm{mol} / 1$ chidamide for $48 \mathrm{~h}$, and HDACs expression was assessed using western blot analysis. The expression of cyclin D1, p53, p-p53, c-myc and p21 in (C) RPMI8226 and (D) U266 cells, whereas Bax, Bcl-2 and mcl-1 in (E) RPMI8226 and (F) U266 cells following chidamide treatment were assessed using western blot analysis. GAPDH served as the internal control in all experiments. HDAC, histone deacetylase; Bcl-2, B-cell lymphoma 2; Bax, apoptosis regulator Bax; mcl-1, myeloid cell leukemia-1; p-, phosphorylated; t-, total; p21, cyclin-dependent kinase inhibitor 1; p53, cellular tumor antigen p53.

enzyme activity, and subsequently induce the acetylation of histones $\mathrm{H} 3$ and $\mathrm{H} 4$ in myeloma cells.

CM downregulates the expression of Bcl-2, mcl-1, c-myc and cyclin D1, and upregulates the expression of p-p53, Bax and $p 21$. To understand the molecular mechanisms involved in $\mathrm{CM}$-induced cell cycle arrest and apoptosis, the protein expression of Bcl-2, Bax, mcl-1, c-myc, p53, p-p53, cyclin D1 and p21 was investigated. As expected, CM treatment markedly deceased cyclin D1 and c-myc expression, but increased p21 and p-p53 expression in a dose-dependent manner, which markedly induced $G_{0} / G_{1}$ arrest (Fig. $4 C$ and $D$ ). The total p53 expression was not changed. CM treatment increased the expression of Bax, but decreased the expression of Bcl-2 and mcl-1 (Fig. 4E and F) in a dose-dependent manner, which may induce cell apoptosis by upregulating the $\mathrm{Bax} / \mathrm{Bcl}-2$ ratio.

CM promotes apoptosis in a caspase-dependent manner. The role of members of the caspase family in CM-induced apoptosis of MM cells was investigated using western blot analysis. The treatment of RPMI8226 and U266 cells with CM for $48 \mathrm{~h}$ induced the cleavage of caspase- 8 , caspase- 9 , caspase- 3 and
PARP in a dose-dependent manner, which is a hallmark of apoptosis (Fig. 5). These results indicate that CM induces apoptosis in a caspase-dependent manner.

CM sensitizes $M M$ cells to BTZ. CM was investigated further to examine whether it enhanced the cytotoxic effect of BTZ on MM cells. RPMI8226 and U266 cells were exposed to CM alone $(0.5 \mu \mathrm{mol} / 1$ for RPMI8226 cells and $2 \mu \mathrm{mol} / 1$ for U266 cells) and in combination with BTZ (2.5 or $5 \mathrm{ng} / \mathrm{ml})$ for $24 \mathrm{~h}$. A low dose of CM slightly suppressed cell viability when used alone; the viability inhibition rate was $12.60 \pm 2.82 \%$ in the RPMI8226 cells and $4.92 \pm 1.28 \%$ in U266. In RPMI8226 cells, compared with $2.5 \mathrm{ng} / \mathrm{ml} \mathrm{BTZ}$ treatment alone, the inhibition rate of BTZ co-treatment with $0.5 \mu \mathrm{mol} / 1 \mathrm{CM}$ for $24 \mathrm{~h}$ increased from $28.11 \pm 2.12$ to $48.84 \pm 2.82 \%$ ( $\mathrm{P}<0.001$ ). In U266 cells, compared with treatment with $2.5 \mathrm{ng} / \mathrm{ml} \mathrm{BTZ}$ alone, the inhibition rate of BTZ co-treatment with $2 \mu \mathrm{mol} / 1 \mathrm{CM}$ for $24 \mathrm{~h}$ increased from $4.35 \pm 1.94$ to $22.83 \pm 1.10 \%$ ( $\mathrm{P}<0.001$; Fig. 6). The combination index $(\mathrm{CI})$ values were calculated using the Chou-Talalay equation (23). The CIs of the low-dose combination were 0.947 and 0.385 in the RPMI8226 and U266 cells, respectively. All of the CIs were $<1$, which suggests a synergistic combination of CM and BTZ at a low dose.

\section{Discussion}

In the present study, CM induced an anti-myeloma effect by decreasing the expression of class I HDACs and increasing the acetylation levels of histones $\mathrm{H} 3$ and $\mathrm{H} 4$. In addition, CM treatment induced $\mathrm{G}_{0} / \mathrm{G}_{1}$ arrest by decreasing the expression of cyclin D1 and c-myc, and increasing the expression of p-p53 and p21. Furthermore, it promoted cell apoptosis by upregulating the $\mathrm{Bax} / \mathrm{Bcl}-2$ ratio in a caspase-dependent manner.

The therapeutic potential of HDACIs in cancer treatment has attracted increased attention and interest. Some well known mechanisms of HDACIs include the regulation of the cell cycle, apoptosis, metastasis, DNA-damage responses (DDRs), autophagy, angiogenesis and other cellular processes (24). CM induces anti-tumor effects through various mechanisms, depending on the type of cancer and its dose. These mechanisms include: i) Cell cycle arrest, CM arrests tumor cells at the $G_{0} / G_{1}$ phase $(12,16,25)$; ii) apoptosis induction, $\mathrm{CM}$ induces apoptosis by regulating the balance of pro- and anti-apoptotic genes, activating intrinsic apoptotic pathways (25); iii) suppression of cellular signaling pathways, CM inhibits the Janus kinase/STAT, PI3K/AKT and mitogen-activated protein kinase/JNK signaling pathways $(16,19,26,27)$; iv) reactive oxygen species generation and induction of DNA damage $(10,25)$; v) energy metabolism modulation, CM suppresses mitochondrial aerobic respiration by downregulation of mcl-1 (20); vi) activation of cellular antitumor immunity mediated by NK cells and antigen-specific cluster of differentiation 8-positive cytotoxic T lymphocytes (11); vii) reversion of transforming growth factor- $\beta$-induced epithelial-mesenchymal transition in tumor cells (28); and viii) upregulation of the tumor suppressor genes Spi-1 proto-oncogene and Krüppel-like factor-4 (29). In the present study, it was demonstrated that $\mathrm{CM}$ serves a role in suppressing the viability of MM cells. The results suggested that $\mathrm{CM}$ was able to inhibit the expression of class I HDACs 


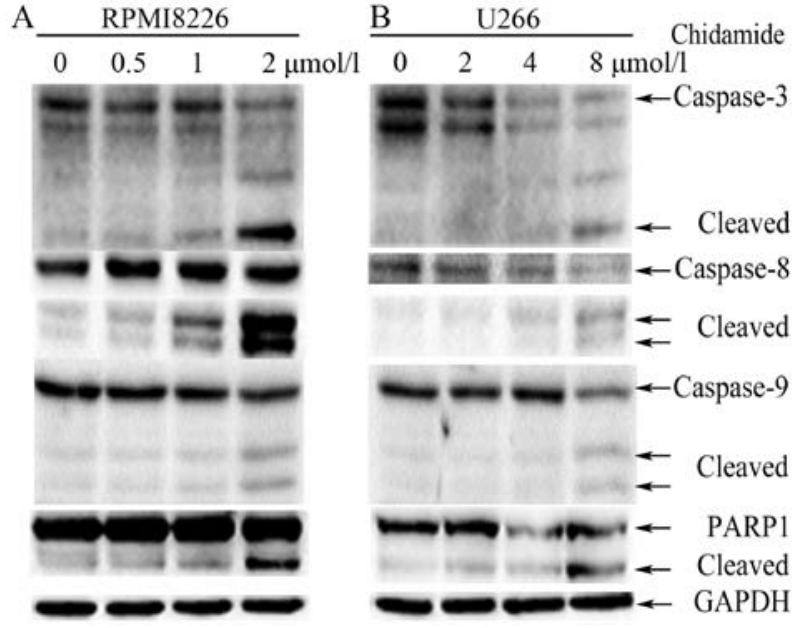

Figure 5. Chidamide induces apoptosis in a caspase-dependent manner in myeloma cells. (A) RPMI8226 cells were treated with $(0,0.5,1,2 \mu \mathrm{mol} / \mathrm{l})$ chidamide for $48 \mathrm{~h}$ and (B) U266 cells were treated with $(0,2,4,8 \mu \mathrm{mol} / \mathrm{l})$ chidamide for $48 \mathrm{~h}$, and then the expression of the cleaved and full-length caspase-8, caspase-9, caspase-3 and PARP was determined using western blot analysis. GAPDH served as the internal control. PARP, poly ADP ribose polymerase.

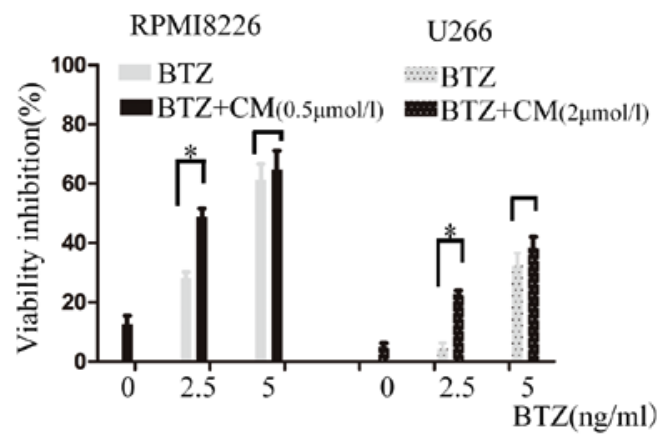

Figure 6. CM sensitizes myeloma cells to BTZ. (A) RPMI8226 and (B) U266 cell lines were exposed to $(2.5 \mathrm{~g} / \mathrm{ml}$ and $5 \mathrm{ng} / \mathrm{ml})$ BTZ alone and in combination with CM $(0.5 \mu \mathrm{mol} / 1$ for RPMI8226 cells and $2 \mu \mathrm{mol} / 1$ for $\mathrm{U} 266$ cells) for $24 \mathrm{~h}$, and subsequently cell viability was evaluated using the Cell Counting Kit-8. "P<0.05. BTZ, bortezomib; CM, chidamide.

and further upregulated the acetylation of histones $\mathrm{H} 3$ and $\mathrm{H} 4$, which confirmed the selective HDACI role of CM in MM. In the present study, the molecular mechanisms underlying cell cycle arrest and apoptosis induction were investigated.

Aberrant cell cycle is considered a hallmark of a number of cancer types. The $G_{1} / S$ checkpoint, which controls the cell cycle transition from $\mathrm{G}_{0} / \mathrm{G}_{1}$ to $\mathrm{S}$-phase, is frequently lost in cancer cells. The 2 cell cycle kinases, cyclin D-cyclin-dependent kinase (CDK)4/6 and cyclin E-CDK2 complexes, are critical in controlling this checkpoint (30). Cyclin D1 is a key cell cycle protein belonging to the $\mathrm{G}_{1}$ phase family. Following activation by extrinsic or intrinsic mitotic signals, cyclin D1 cooperates with CDK $4 / 6$ to drive the cell cycle progression from $G_{0} / G_{1}$ to $S$ phase by phosphorylating retinoblastoma $(\mathrm{RB})$ and releasing $\mathrm{E} 2$ factor (E2F) (31). In addition, cyclin D1 overexpression is significantly associated with tumor invasiveness and metastasis (32). p21 protein, a CDK inhibitor, can regulate the cell cycle transition from $\mathrm{G}_{0} / \mathrm{G}_{1}$ to $\mathrm{S}$-phase in response to a number of stimuli (33). p21 binds to and inhibits the activity of cyclin E/CDK2, which decreases the CDK2-dependent phosphorylation of RB and E2F1-dependent gene transcription (34). p21 is primarily regulated by the DDR kinases ataxia-telangiectasia mutated (ATM), p53 and checkpoint kinase 2 (Chk2) (35). At this checkpoint, p53 can be activated by Chk2 and ATM, thus causing inhibition of cyclin E/CDK2. The c-myc protein, a transcription factor, can drive cell proliferation by the upregulation of CDKs, cyclins and E2F transcription factors, as well as the downregulation of p15, p16, p21 and p27 (36). Previous studies revealed that almost all HDACIs, including TF2357, valproate, LBH589, NVP-LAQ824, sodium butyrate and suberoylanilide hydroxamic acid (SAHA), induce $G_{0} / G_{1}$ arrest due to the upregulation of $C D K$ inhibitor by $\mathrm{p} 53$-dependent and -independent mechanisms in MM cells (37-42). Similarly, it has been reported that treatment with $\mathrm{CM}$ induces $\mathrm{G}_{0} / \mathrm{G}_{1}$ cell cycle arrest in a number of cancer types. In NK/T-cell lymphoma cell lines, CM decreases cyclin E expression, increases p21 expression and activates the DDR cell cycle checkpoint pathway (ATM-Chk2-p53-p21 pathway) (16). In colon cancer cells, CM increases the level of p53, p-p53 and p21, but suppresses CDK4 (43). In myelodysplastic syndromes, CM downregulates CDK2 and upregulates p-p53 and p21 protein expression (12). The data from the present study revealed that $C M$ promotes $G_{0} / G_{1}$ cell cycle arrest in $M M$ cells. p53 is mutated in the myeloma cell lines RPMI8226 and U266 (44). Although p53 expression was not changed following $\mathrm{CM}$ treatment, the expression of p-p53 and its downstream target p21 were increased, whereas the expression of c-myc and cyclin D1 were decreased, suggesting that activation of the DDR cell cycle checkpoint pathway may contribute, at least in part, to $\mathrm{CM}$-induced $\mathrm{G}_{0} / \mathrm{G}_{1}$ arrest in $\mathrm{MM}$.

Induction of apoptosis has been revealed to be a promising strategy for the development of novel anticancer agents. HDACIs can induce the intrinsic and extrinsic apoptotic pathways (45). HDACIs upregulate the Bcl-2 family proteins (Bax, Noxa, BH3-interacting domain death agonist, BCL-2-like protein 11, Bcl-2 homologous antagonist killer and Bcl-2-binding component 3), but downregulate anti-apoptotic Bcl-2 family proteins (mcl-1, Bcl-2 and Bcl-xl), thus activating the intrinsic pathway. Previous studies investigating the treatment of HDACIs (KD5170, depsipeptide, ITF2357, SAHA and LBH589) in MM cells found increased mitochondrial permeability and cytosolic release of cytochrome $c$ and second mitochondria-derived activator of caspases following activation of the intrinsic pathway $(37,39,42,46,47)$. On the other hand, HDACIs increase the expression of tumor necrosis factor-related apoptosis-inducing ligand (TRAIL) receptors and their susceptibility to TRAIL-induced extrinsic apoptosis, as seen in MM cells following LBH589, valproate and SAHA treatment $(39,42,48)$. Similarly, it has been reported that treatment with $\mathrm{CM}$ induces the intrinsic pathway in a number of cancer types. In the NK/T-cell lymphoma cell lines, CM downregulates Bcl-2 and induces the cleavage of PARP, suggesting a mitochondria-mediated caspase-dependent apoptotic pathway (16). In pancreatic cancer, CM upregulates the $\mathrm{Bax} / \mathrm{Bcl}-2$ ratio, thus suppressing cellular proliferation by promoting mitochondrial pathway-dependent cell apoptosis (25). In leukemia cell lines, CM increases Bcl-2 family protein expression and promotes the generation of reactive oxygen species, mitochondrial dysfunction and cytochrome $c$ release, inducing caspase-dependent apoptosis $(13,27,49)$. The 
data from the present study revealed that $\mathrm{CM}$ induces apoptosis in MM cells in a time- and dose-dependent manner. CM activates caspase- 3 , caspase- 8 , caspase- 9 and PARP, and increases the $\mathrm{Bax} / \mathrm{Bcl}-2$ expression ratio, promoting mitochondrial pathway-dependent cell apoptosis in MM cells.

The present study has several limitations. First, the most common types of inhibitors of apoptosis include the Bcl-2 family and inhibitor of apoptosis proteins (IAP) family. As apoptosis was induced by $\mathrm{CM}$, only the effect of $\mathrm{CM}$ on $\mathrm{Bcl}-2$ family (downregulation of mcl-1 and Bcl-2) was investigated, but whether CM can decrease IAP expression will be explored in future experiments. Secondly, it was revealed that CM treatment increased the sensitivity against BTZ in myeloma cells, however, the possible mechanisms involved were not investigated, requiring further study. Thirdly, the anti-myeloma effect of CM was examined only in vitro, therefore the effect should also be investigated in vivo.

In conclusion, it was demonstrated that $\mathrm{CM}$ induces an anti-myeloma effect. $C M$ promotes $\mathrm{G}_{0} / \mathrm{G}_{1}$ arrest and apoptosis in myeloma cells in a caspase-dependent manner. Future studies will focus on the in vivo efficacy of this treatment and define the optimal combination regimens. The present study provides evidences for the clinical administration of CM in MM.

\section{Acknowledgements}

Not applicable.

\section{Funding}

This study was supported by the Zhejiang Provincial Key Innovation Team (grant no. 2011R50015), the National Natural Science Foundation of China (grant no. 81572920), the National Basic Research Program of China (grant no. 2013CB911303) and the Natural Science Foundation of Zhejiang Province of China (grant no. LY15H160038).

\section{Availability of data and materials}

All data generated or analyzed during this study are included in this published article.

\section{Authors' contributions}

XGY performed the research and wrote the manuscript. YRH, TY and HWJ performed the research. YX performed the statistical analysis. XYZ designed and supervised the research project. All authors read and approved the final manuscript.

\section{Ethics approval and consent to participate}

This study has been approved by the Ethics Committee of The Second Affiliated Hospital, Zhejiang University School of Medicine (Hangzhou, China), and written informed consent was obtained from all participants.

\section{Patient consent for publication}

The study participants provided consent for the data to be published.

\section{Competing interests}

The authors declare that they have no competing interests.

\section{References}

1. Siegel RL, Miller KD and Jemal A: Cancer statistics, 2018. CA Cancer J Clin 68: 7-30, 2018.

2. Palumbo A and Anderson K: Multiple myeloma. N Engl J Med 364: 1046-1060, 2011.

3. Siegel RL, Miller KD and Jemal A: Cancer statistics, 2016. CA Cancer J Clin 66: 7-30, 2016.

4. Mithraprabhu S, Kalff A, Chow A, Khong T and Spencer A: Dysregulated Class I histone deacetylases are indicators of poor prognosis in multiple myeloma. Epigenetics 9: 1511-1520, 2014.

5. Moreaux J, Reme T, Leonard W, Veyrune JL, Requirand G, Goldschmidt H, Hose D and Klein B: Gene expression-based prediction of myeloma cell sensitivity to histone deacetylase inhibitors. Br J Cancer 109: 676-685, 2013.

6. Dimopoulos M, Siegel DS, Lonial S, Qi J, Hajek R, Facon T, Rosinol L, Williams C, Blacklock H, Goldschmidt H, et al: Vorinostat or placebo in combination with bortezomib in patients with multiple myeloma (VANTAGE 088): A multicentre, randomised, double-blind study. Lancet Oncol 14: 1129-1140, 2013.

7. San-Miguel JF, Hungria VT, Yoon SS, Beksac M, Dimopoulos MA, Elghandour A, Jedrzejczak WW, Günther A, Nakorn TN, Siritanaratkul N, et al: Panobinostat plus bortezomib and dexamethasone versus placebo plus bortezomib and dexamethasone in patients with relapsed or relapsed and refractory multiple myeloma: A multicentre, randomised, double-blind phase 3 trial. Lancet Oncol 15: 1195-1206, 2014.

8. Raje NS, Bensinger W, Cole CE, Lonial S, Jagannath S Arce-Lara CE, Valent J Rosko AE, Harb WA, Sandhu PG, et al: Ricolinostat (ACY-1215), the first selective HDAC6 inhibitor, combines safely with pomalidomide and dexamethasone and shows promosing early results in relapsed-and- refractory myeloma (ACE-MM-102 Study). Blood 126: 4228, 2015.

9. Bradner JE, West N, Grachan ML, Greenberg EF, Haggarty SJ, Warnow T and Mazitschek R: Chemical phylogenetics of histone deacetylases. Nat Chem Biol 6: 238-243, 2010.

10. Pan DS, Yang QJ, Fu X, Shan S, Zhu JZ, Zhang K, Li ZB, Ning Q and Lu XP: Discovery of an orally active subtype-selective HDAC inhibitor, chidamide, as an epigenetic modulator for cancer treatment. Med Chem Commun 5: 1789-1796, 2014.

11. Ning ZQ,LiZB, Newman MJ, Shan S, Wang XH, Pan DS, Zhang J, Dong M, Du X and Lu XP: Chidamide (CS055/HBI-8000): A new histone deacetylase inhibitor of the benzamide class with antitumor activity and the ability to enhance immune cell-mediated tumor cell cytotoxicity. Cancer Chemoth Pharm 69: 901-909, 2012.

12. Liu Z, Ding K, Li L, Liu H, Wang Y, Liu C and Fu R: A novel histone deacetylase inhibitor Chidamide induces G0/G1 arrest and apoptosis in myelodysplastic syndromes. Biomed Pharmacother 83: 1032-1037, 2016.

13. Gong K, Xie J, Yi H and Li W: CS055 (Chidamide/HBI-8000), a novel histone deacetylase inhibitor, induces G1 arrest, ROS-dependent apoptosis and differentiation in human leukaemia cells. Biochem J 443: 735-746, 2012.

14. Li X, Yan X, Guo W, Huang X, Huang J, Yu M, Ma Z, Xu Y, Huang S, Li C, et al: Chidamide in FLT3-ITD positive acute myeloid leukemia and the synergistic effect in combination with cytarabine. Biomed Pharmacother 90: 699-704, 2017.

15. Shi P, Zhang L, Chen K, Jiang Z, Deng M, Zha J, Guo X, Li P and Xu B: Low-dose decitabine enhances chidamide-induced apoptosis in adult acute lymphoblast leukemia, especially for p16-deleted patients through DNA damage. Pharmacogenomics 18: 1259-1270, 2017.

16. Zhou J, Zhang C, Sui X, Cao S, Tang F, Sun S, Wang S and Chen B: Histone deacetylase inhibitor chidamide induces growth inhibition and apoptosis in NK/T lymphoma cells through ATM-Chk2-p53-p21 signalling pathway. Invest New Drugs 36: 571-580, 2018.

17. Zhou Y, Pan DS, Shan S, Zhu JZ, Zhang K, Yue XP, Nie LP, Wan J, Lu XP, Zhang W and Ning ZQ: Non-toxic dose chidamide synergistically enhances platinum-induced DNA damage responses and apoptosis in non-small-cell lung cancer cells. Biomed Pharmacother 68: 483-491, 2014. 
18. Wang H, Guo Y, Fu M, Liang X, Zhang X, Wang R, Lin C and Qian H: Antitumor activity of Chidamide in hepatocellular carcinoma cell lines. Mol Med Rep 5: 1503-1508, 2012.

19. Liu L, Chen B, Qin S, Li S, He X, Qiu S, Zhao W and Zhao H: A novel histone deacetylase inhibitor Chidamide induces apoptosis of human colon cancer cells. Biochem Biophys Res Commun 392: 190-195, 2010.

20. He M, Qiao Z, Wang Y, Kuai Q, Li C, Wang Y, Jiang X, Wang X, Li W, He M, et al: Chidamide inhibits aerobic metabolism to induce pancreatic cancer cell growth arrest by promoting Mcl-1 degradation. PLoS One 11: e0166896, 2016.

21. Gu R, Liu T, Zhu X, Gan H, Wu Z, Li J, Zheng Y, Dou G and Meng Z: Development and validation of a sensitive HPLC-MS/MS method for determination of chidamide (epidaza), a new benzamide class of selective histone deacetylase inhibitor, in human plasma and its clinical application. J Chromatogr B Analyt Technol Biomed Life Sci 1000: 181-186, 2015.

22. Shi Y, Jia B, Xu W, Li W, Liu T, Liu P, Zhao W, Zhang H, Sun X, Yang $\mathrm{H}$, et al: Chidamide in relapsed or refractory peripheral T cell lymphoma: A multicenter real-world study in China. J Hematol Oncol 10: 69, 2017.

23. Chou TC: Drug combination studies and their synergy quantification using the Chou-Talalay method. Cancer Res 70: 440-446, 2010.

24. Bose P, Dai Y and Grant S: Histone deacetylase inhibitor (HDACI) mechanisms of action: Emerging insights. Pharmacol Ther 143: 323-336, 2014.

25. Zhao B and He T: Chidamide, a histone deacetylase inhibitor, functions as a tumor inhibitor by modulating the ratio of Bax/Bcl-2 and P21 in pancreatic cancer. Oncol Rep 33: 304-310, 2015.

26. Li Y, Chen K, Zhou Y, Xiao Y, Deng M, Jiang Z, Ye W, Wang X, Wei X, Li J,et al: A new strategy to target acute myeloid leukemia stem and progenitor cells using chidamide, a histone deacetylase inhibitor. Curr Cancer Drug Targets 15: 493-503, 2015.

27. Zhao S, Guo J, Zhao Y, Fei C, Zheng Q, Li X and Chang C: Chidamide, a novel histone deacetylase inhibitor, inhibits the viability of MDS and AML cells by suppressing JAK2/STAT3 signaling. Am J Transl Res 8: 3169-3178, 2016.

28. Lin SH, Wang BY, Lin CH, Chien PJ, Wu YF, Ko JL and Chen JJ: Chidamide alleviates TGF- $\beta$-induced epithelial-mesenchymal transition in lung cancer cell lines. Mol Biol Rep 43: 687-695, 2016.

29. Jiang T, Wang F, Hu L, Cheng X, Zheng Y, Liu T and Jia Y: Chidamide and decitabine can synergistically induce apoptosis of Hodgkin lymphoma cells by up-regulating the expression of PU.1 and KLF4. Oncotarget 8: 77586-77594, 2017.

30. Lundberg AS and Weinberg RA: Functional inactivation of the retinoblastoma protein requires sequential modification by at least two distinct cyclin-cdk complexes. Mol Cell Biol 18 753-761, 1998

31. Fu M, Wang C, Li Z, Sakamaki T and Pestell RG: Minireview: Cyclin D1: Normal and abnormal functions. Endocrinology 145: 5439-5447, 2004.

32. Imoto M, Doki Y, Jiang W, Han EK and Weinstein IB: Effects of cyclin D1 overexpression on G1 progression-related events. Exp Cell Res 236: 173-180, 1997.

33. Karimian A, Ahmadi Y and Yousefi B: Multiple functions of $\mathrm{p} 21$ in cell cycle, apoptosis and transcriptional regulation after DNA damage. DNA Repair (Amst) 42: 63-71, 2016.

34. Abbas T and Dutta A: p21 in cancer: Intricate networks and multiple activities. Nat Rev Cancer 9: 400-414, 2009.

35. Hirao A, Kong YY, Matsuoka S, Wakeham A, Ruland J, Yoshida H, Liu D, Elledge SJ and Mak TW: DNA damageinduced activation of 553 by the checkpoint kinase Chk2 Science 287: 1824-1827, 2000.
36. Bretones G, Delgado MD and León J: Myc and cell cycle control Biochim Biophys Acta 1849: 506-516, 2015.

37. Golay J, Cuppini L, Leoni F, Micò C, Barbui V, Domenghini M, Lombardi L, Neri A, Barbui AM, Salvi A, et al: The histone deacetylase inhibitor ITF2357 has anti-leukemic activity in vitro and in vivo and inhibits IL-6 and VEGF production by stromal cells. Leukemia 21: 1892-1900, 2007.

38. Kaiser M, Zavrski I, Sterz J, Jakob C, Fleissner C, Kloetzel PM, Sezer O and Heider U: The effects of the histone deacetylase inhibitor valproic acid on cell cycle, growth suppression and apoptosis in multiple myeloma. Haematologica 91: 248-251, 2006.

39. Maiso P, Carvajal-Vergara X, Ocio EM, López-Pérez R, Mateo G, Gutiérrez N, Atadja P, Pandiella A and San Miguel JF: The histone deacetylase inhibitor LBH589 is a potent antimyeloma agent that overcomes drug resistance. Cancer Res 66: 5781-5789, 2006.

40. Catley L, Weisberg E, Tai YT, Atadja P, Remiszewski S, Hideshima T, Mitsiades N, Shringarpure R, LeBlanc R, Chauhan D, et al: NVP-LAQ824 is a potent novel histone deacetylase inhibitor with significant activity against multiple myeloma. Blood 102: 2615-2622, 2003.

41. Lavelle D, Chen YH, Hankewych $\mathrm{M}$ and DeSimone J: Histone deacetylase inhibitors increase p21(WAF1) and induce apoptosis of human myeloma cell lines independent of decreased IL-6 receptor expression. Am J Hematol 68: 170-178, 2001.

42. Mitsiades N, Mitsiades CS, Richardson PG, McMullan C, Poulaki V, Fanourakis G, Schlossman R, Chauhan D, Munshi NC, Hideshima T, et al: Molecular sequelae of histone deacetylase inhibition in human malignant B cells. Blood 101: 4055-4062, 2003.

43. Liu L, Qiu S, Liu Y, Liu Z, Zheng Y, Su X, Chen B and Chen H: Chidamide and 5-flurouracil show a synergistic antitumor effect on human colon cancer xenografts in nude mice. Neoplasma 63 : 193-200, 2016

44. Mazars GR, Portier M, Zhang XG, Jourdan M, Bataille R, Theillet $C$ and Klein B: Mutations of the p53 gene in human myeloma cell lines. Oncogene 7: 1015-1018, 1992.

45. Miller CP, Singh MM, Rivera-Del Valle N, Manton CA and Chandra J: Therapeutic strategies to enhance the anticancer efficacy of histone deacetylase inhibitors. J Biomed Biotechnol 2011: 514261,2011

46. Feng R, Ma H, Hassig CA, Payne JE, Smith ND, Mapara MY, Hager JH and Lentzsch S: KD5170, a novel mercaptoketone-based histone deacetylase inhibitor, exerts antimyeloma effects by DNA damage and mitochondrial signaling. Mol Cancer Ther 7: 1494-1505, 2008

47. Khan SB, Maududi T, Barton K, Ayers J and Alkan S: Analysis of histone deacetylase inhibitor, depsipeptide (FR901228), effect on multiple myeloma. Br J Haematol 125: 156-161, 2004.

48. Schwartz C, Palissot V, Aouali N, Wack S, Brons NH, Leners B Bosseler M and Berchem G: Valproic acid induces non-apoptotic cell death mechanisms in multiple myeloma cell lines. Int $\mathbf{J}$ Oncol 30: 573-582, 2007.

49. Li Y, Chen K, Zhou Y, Xiao Y, Deng M, Jiang Z, Ye W, Wang X, Wei X, Li J, et al: A new strategy to target acute myeloid leukemia stem and progenitor cells using chidamide, a histone deacetylase inhibitor. Curr Cancer Drug Targets 15: 493-503, 2015.

This work is licensed under a Creative Commons Attribution-NonCommercial-NoDerivatives 4.0 International (CC BY-NC-ND 4.0) License. 